\title{
CORRIGENDA
}

\section{Corrigenda: Genomic signatures to guide the use of chemotherapeutics}

Anil Potti, Holly K Dressman, Andrea Bild, Richard F Riedel, Gina Chan, Robyn Sayer, Janiel Cragun, Hope Cottrill, Michael J Kelley, Rebecca Petersen, David Harpole, Jeffrey Marks, Andrew Berchuck, Geoffrey S Ginsburg, Phillip Febbo, Johnathan Lancaster \& Joseph R Nevins

Nat. Med. 12, 1294-1300 (2006); published online 22 October 2006; corrected after print 10 May and 10 October 2007

In the supplementary information initally published online to accompany this article, and in the revised supplementary information posted online on 10 May, the gene lists that make up the chemotherapy sensitivity signatures in Supplementary Table 1 contained errors. The errors have been corrected online. 